\title{
Knowledge, Attitude and Practice Regarding Stroke amongst the Close Relatives of Stroke Victims at a Tertiary Care Hospital in Bangladesh
}

\author{
Adnan Bashir Bhat", Kazi Ishraque Ahmed, Rubaiya Naushin Sharna, Sreekanta Barman \\ Shaheed Suhrawardy Medical College and Hospital, Sher-e-Bangla Nagor, Dhaka -1207, Bangladesh
}

Copyright $(2016$ by authors, all rights reserved. Authors agree that this article remains permanently open access under the terms of the Creative Commons Attribution License 4.0 International License

\begin{abstract}
Background and Purpose: Stroke is one of the most commonly encountered neurological emergencies in Tertiary Care Hospitals and is one of the leading causes of death in Bangladesh. Poor knowledge of risk factors, symptoms and appropriate response are possible causes of poor outcome. There are no studies from Bangladesh regarding knowledge about warning symptoms and risk factors amongst stroke patients or their families. We aimed to assess the knowledge, attitude and practice regarding stroke amongst close relatives of stroke patients. Methods: We performed a descriptive cross-sectional questionnaire survey amongst close relatives of acute stroke cases who were admitted under various Medicine units in Shaheed Suhrawardy Medical College \& Hospital. Stroke knowledge was excellent if a participant knew (1) at least 2 stroke symptoms (good symptom knowledge) and (2) at least 2 stroke risk factors (good risk factor knowledge), as well as knowing (3) that immediate hospital admission is necessary in case of stroke (good action knowledge). Participants who had studied up to elementary school were considered having lower educational qualification and participants who were under graduates or having higher qualification were considered having higher educational qualification. Results: One hundred and eighty six (186) acute stroke cases were admitted during our study period of which 110 cases matched our criteria and were willing to give informed written consent. Of the 110 participants interviewed, 45 $(40.9 \%)$ were males and $65(59.1 \%)$ were females. Mean age was 35.2 years (S.D 11.5 years). Good risk factor knowledge was seen in $63.6 \%$ while $73.6 \%$ had good symptom knowledge and $98.2 \%$ had good action knowledge. Stroke knowledge was excellent in $52.7 \%$ of subjects. The most common identified stroke risk factor was Stress $(n=75$, $80.6 \%$ ) and the most common identified symptom was Weakness/paralysis of one side of body $(n=67,76.1 \%)$. Higher educational qualification was associated with good risk factor knowledge $(P=0.009)$ and excellent stroke knowledge $(P=0.020)$. Eighty-one $(73.6 \%)$ participants had
\end{abstract}

never heard about the importance of receiving therapy within the first four and half hours (golden hours) after the onset of symptoms of stroke. Stroke knowledge and perception was not significantly related to other variables of age, sex, religion and income $(P>0.05)$. Conclusions: In this study, in general, there is lack of awareness of major risk factors, warning symptoms, organ involvement, treatment options and the importance of the golden hours. However, higher educational status was associated with better risk factor knowledge and excellent stroke knowledge. Educational strategies to increase stroke knowledge are definitely needed as a prelude to developing preventive programs. By using primary health care resources, public media and organizing health camps, it is possible to promote the level of knowledge, practice and attitude regarding stroke in Bangladeshi population.

Keywords Stroke, Knowledge, Risk Factors, Bangladesh, Awareness, Attitude, Education

\section{Introduction}

Stroke is one of the most commonly encountered neurological emergencies in Tertiary Care Hospitals and is one of the leading causes of death in Bangladesh [1]. World Heath Organization (WHO) defines stroke as rapidly developed clinical signs of focal disturbance of cerebral function lasting for more than 24 hours or leading to death without any apparent cause other than vascular origin [2]. Despite recent advances in stroke therapy, the majority of stroke patients do not seek immediate medical attention [3, 4]. Stroke may present with an array of signs and symptoms such as weakness or numbness involving one or both sides of the body, headache, vertigo, vomiting, cranial nerve deficits and visual disturbances. Risk factors for stroke 
include non-modifiable factors like age, sex and modifiable factors like hypertension, heart disease, diabetes mellitus, hyperlipidemia, smoking and excess alcohol intake [5]. Lack of information and poor control of risk factors contribute to the rising incidence of stroke in developing countries. Therefore, by early detection and reduction of these modifiable risk factors, it is possible to reduce the incidence of stroke and this is influenced by the public knowledge and perception of stroke and its risk factors. The aim of the present study is to assess baseline knowledge regarding stroke risk factors, symptoms, importance of receiving early treatment (within first few hours of onset of symptoms) in acute stroke, treatment modalities and information resources from relatives of patients admitted with acute stroke using a structured questionnaire.

\section{Materials and Methods}

A descriptive cross-sectional study was conducted over a month amongst close relatives of acute stroke cases who were admitted under various Medicine units in Shaheed Suhrawardy Medical College \& Hospital (Sh.SMCH). Sh.SMCH is an 850 bedded multidisciplinary hospital located in Sher-e-Bangla Nagar, Dhaka. Being a tertiary care hospital, patients are admitted from Out Patient Department (OPD), emergency department or after being referred from other health care facilities. The study was done based on a structured self-administered questionnaire that assessed the demographic variables, knowledge regarding stroke risk factors and symptoms, attitude and the general practices adopted by close relatives of stroke patients in such situations through face to face interviews. The questionnaire was developed from a similar instrument used by Kothari, et al from the University of Cincinnati [6] with additional input obtained from Weltermann BM, et al [7]. The inclusion criteria comprised of being a close relative of acute stroke patient (Computed Tomography proven), minimum age of 18 years and willingness to give informed written consent. We excluded relatives of patients dying within 24 hours of acute stroke. Purposive sampling was done amongst the close relatives of stroke patients admitted through OPD and emergency departments during our study period. Informed written consent was taken and no investigations, treatment or any sort of intervention was made on behalf of the investigators. Ethical approval for this study was obtained from the Ethical Review Committee of Shaheed Suhrawardy Medical College and Hospital through reference no: ShSMCH/Ethical/2016/14.

\subsection{Questions Assessing Stroke Knowledge}

Using our questionnaire, we asked participants to list stroke symptoms, risk factors, body part affected and the complications that may arise due to stroke. Also, the appropriate action needed to be taken in case of stroke symptoms and the critical four and half hours time interval were addressed. According to our definition, a participant had excellent stroke knowledge if all of the following 3 criteria were met: (1) participant knew at least 2 stroke symptoms (good symptom knowledge) and (2) at least 2 stroke risk factors (good risk factor knowledge), as well as knowing (3) that immediate hospital admission is necessary in case of stroke (good action knowledge). Participants who had studied up to elementary school were considered having lower educational qualification and participants who were under graduates or having higher qualification were considered having higher educational qualification. Participants with monthly income of less than or equal to Bangladeshi Taka (BDT) fifteen thousand (equal to one hundred and ninety US Dollars) were considered having low income and those with monthly income above BDT fifteen thousand (one hundred and ninety US Dollars) were considered having moderate/high income status. This methodology was validated through similar studies conducted earlier by Weltermann BM, et al [7].

\subsection{Statistical Analysis}

Data was collected, coded and analyzed using SPSS software (version 23; SPSS Inc., Chicago, Illinois, USA). Descriptive statistics of mean, frequency and percentages were used to summarize data on socio-demographic variables and stroke knowledge and perceptions. $\mathrm{X}^{2}$ (chi square) tests were used to assess associations between stroke knowledge and perception with demographic variables. Variables in the model included age (less than and equal to or more than 50 years), gender, religion (Muslims vs. others), education (lower educational qualification vs. higher educational qualification) and income (low income vs. moderate/high income). P-value less than or equal to 0.05 was considered statistically significant.

\section{Results}

The demographic characteristics of the participants are given in table 1. Stressful life was the most cited risk factor followed by hypertension and diabetes mellitus (table 4). Of the 110 participants, $32(54.2 \%)$ agreed that controlling blood pressure could prevent stroke. Seventy-six (69.1\%) participants cited brain as the primary organ of damage in stroke while $32(29.1 \%)$ thought it occurred in the heart. Seventeen $(15.5 \%)$ of the participants failed to cite any stroke risk factors while 22 (20\%) participants failed to cite any stroke warning symptoms. Only $58(52.7 \%)$ of the participants thought stroke is preventable up to a certain extent. Seventy $(63.6 \%)$ respondents thought stroke can be cured and only $29(26.4 \%)$ participants had heard about the importance of receiving therapy within the golden hours ( $4 \frac{1}{2}$ hours after onset of stroke symptoms). Ninety-one $(82.7 \%)$ of the respondents thought that medication is the 
treatment option of stroke while $65(59.1 \%)$ cited physiotherapy as the treatment and only $6(5.5 \%)$ said Surgery is the treatment option (table 2). One hundred and eight (98.2\%) participants thought stroke is an emergency and $99(90 \%)$ participants said they would go to a nearby hospital if they/their family member developed warning signs of stroke. Of the 110 participants, $50(45.5 \%)$ said that cost of treatment would inhibit them from seeking health care facilities, $36(32.7 \%)$ said that difficult transportation was an inhibiting factor while $38(34.5 \%)$ said nothing would inhibit them from seeking healthcare facilities (table 3). One hundred and two (92.7\%) respondents said they wished to learn more about stroke in the future and 72 (65.5\%) pointed out that health care workers could educate them more about stroke. Thirty-three $(30 \%)$ preferred learning through TV while 27 (24.5\%) favored health camps/programs to spread awareness regarding stroke (table 3). Ninety-one (82.7\%) of the participants thought there is need of follow-up of stroke patients after discharge. Seventy-three $(66.4 \%)$ participants thought stroke is best managed at Tertiary Care Hospitals while 18 (16.4\%) thought its best managed at Private Hospitals.

Table 1. Demographic characteristics of the 110 respondents

\begin{tabular}{|c|c|}
\hline Characteristics & Value \\
\hline Age (years) & $35.25 \pm 11.57$ \\
\hline \multicolumn{2}{|l|}{ Sex } \\
\hline Male & $45(40.9 \%)$ \\
\hline Female & $65(59.1 \%)$ \\
\hline \multicolumn{2}{|l|}{ Religion } \\
\hline Islam & $102(92.7 \%)$ \\
\hline Hinduism & $8(7.3 \%)$ \\
\hline Others & 0 \\
\hline \multicolumn{2}{|l|}{ Marital Status } \\
\hline Single & $22(20.2 \%)$ \\
\hline Married & $85(78 \%)$ \\
\hline Divorced & $1(0.9 \%)$ \\
\hline Widowed & $1(0.9 \%)$ \\
\hline Other & 0 \\
\hline \multicolumn{2}{|l|}{ Educational Qualification } \\
\hline Higher Qualification & $33(30 \%)$ \\
\hline Lower Qualification & $77(70 \%)$ \\
\hline \multicolumn{2}{|l|}{ Income } \\
\hline High/Moderate & $31(28.2 \%)$ \\
\hline Low & $79(71.8 \%)$ \\
\hline
\end{tabular}

Table 2. Reactions in a case of acute stroke, prevention and treatment of stroke

\begin{tabular}{cc}
\hline $\begin{array}{l}\text { Reactions in a case of acute stroke, } \\
\text { prevention and treatment of stroke }\end{array}$ & Frequency \\
\hline Reaction & \\
Go to a nearby hospital & $99(90 \%)$ \\
Wait and observe & $5(4.5 \%)$ \\
Consult a neurologist & $4(3.6 \%)$ \\
Go to a local doctor & $2(1.8 \%)$ \\
Go to a family physician & $1(0.9 \%)$ \\
Go to a Spiritual Leader & $1(0.9 \%)$ \\
Other & $4(3.6 \%)$ \\
Prevention & (n=58,52.7\%) \\
Control of Blood Pressure & $32(54.2 \%)$ \\
Control of Diabetes & $16(27.1 \%)$ \\
Lifestyle Modification & $13(22 \%)$ \\
Regular check-up with doctor & $10(16.9 \%)$ \\
Reduced Smoking/Alcohol Intake & $8(13.6 \%)$ \\
Don't Know & $2(3.4 \%)$ \\
Other & $30(50.8 \%)$ \\
Treatment Options & \\
Medicine & $91(82.7 \%)$ \\
Physiotherapy & $65(59.1 \%)$ \\
Surgery & $6(5.5 \%)$ \\
Witchcraft/Spiritual & $4(3.6 \%)$ \\
Herbal & $2(1.8 \%)$ \\
Don't Know & $5(4.5 \%)$ \\
Others & $7(6.4 \%)$ \\
\hline
\end{tabular}

Table 3. Attitude of participants towards Stroke treatment and raising awareness

\begin{tabular}{cc}
\hline $\begin{array}{c}\text { Reaction of participants towards } \\
\text { Stroke treatment and raising } \\
\text { awareness }\end{array}$ & Frequency \\
\hline $\begin{array}{c}\text { Factor inhibiting participant from } \\
\text { seeking health care facility } \\
\text { Cost }\end{array}$ & \\
Nothing & $50(45.5 \%)$ \\
Difficult transportation & $38(34.5 \%)$ \\
Distance from home & $36(32.7 \%)$ \\
Not sure where to go & $4(3.6 \%)$ \\
Don't want to find out what's wrong & $2(1.8 \%)$ \\
Others & $1(0.9 \%)$ \\
Expense of stroke management in & $8(7.3 \%)$ \\
Bangladesh $\quad$ \\
Very Expensive & \\
Slightly Expensive & $56(50.9 \%)$ \\
Reasonably Priced & $27(24.5 \%)$ \\
Don't Know & $22(20 \%)$ \\
Free & $4(3.6 \%)$ \\
Media to generate further awareness & $1(0.9 \%)$ \\
regarding Stroke in Bangladesh & \\
Healthcare Workers & \\
TV & $72(65.5 \%)$ \\
Health Programs/Camps & $33(30 \%)$ \\
Newspapers/Magazines & $27(24.5 \%)$ \\
Family Friends & $16(14.5 \%)$ \\
Radio & $8(7.3 \%)$ \\
\hline & $6(5.5 \%)$ \\
\hline & $5(4.5 \%)$ \\
\hline & $3(2.7 \%)$ \\
\hline
\end{tabular}


Table 4. "Knowledge of the 110 " respondents about stroke risk factors, warning signs and complications

\begin{tabular}{|c|c|}
\hline $\begin{array}{c}\text { Risk factors/Warning } \\
\text { symptoms/Complications }\end{array}$ & Correct \\
\hline Risk Factors & $(n=93,84.5 \%)$ \\
\hline Stress & $75(80.6 \%)$ \\
\hline High Blood Pressure & $62(66.7 \%)$ \\
\hline Diabetes Mellitus & $20(21.5 \%)$ \\
\hline Smoking & $11(11.8 \%)$ \\
\hline Heart Disease & $8(8.6 \%)$ \\
\hline Old Age & $6(6.5 \%)$ \\
\hline High Cholesterol & $5(5.4 \%)$ \\
\hline Genetics & $5(5.4 \%)$ \\
\hline Alcohol Intake & $3(3.2 \%)$ \\
\hline Obesity & $2(2.2 \%)$ \\
\hline Familial & $1(1.1 \%)$ \\
\hline Others & $18(19.4 \%)$ \\
\hline Warning Signs & $(n=88,80 \%)$ \\
\hline Weakness/Paralysis of one side of body & $67(76.1 \%)$ \\
\hline Sudden difficulty in speaking & $42(47.7 \%)$ \\
\hline Facial deviation & $27(30.7 \%)$ \\
\hline Unconsciousness & $24(27.3 \%)$ \\
\hline Paralysis of any part of the body & $17(19.3 \%)$ \\
\hline Headache & $13(14.8 \%)$ \\
\hline Blurred/double/loss of vision & $11(12.5 \%)$ \\
\hline Vomiting/Nausea & $10(11.4 \%)$ \\
\hline Convulsion & $9(10.2 \%)$ \\
\hline Urinary/Bowel Incontinence & $4(4.5 \%)$ \\
\hline Pain & $2(2.3 \%)$ \\
\hline Chest pain/Tightness & $1(1.1 \%)$ \\
\hline Others & $20(22.7 \%)$ \\
\hline Complications & $(n=87,79.1 \%)$ \\
\hline Permanent disability & $69(79.3 \%)$ \\
\hline Death & $37(42.5 \%)$ \\
\hline Recurrence & $7(8 \%)$ \\
\hline Bed Sore & $6(6.9 \%)$ \\
\hline Depression & $6(6.9 \%)$ \\
\hline Respiratory Distress & $4(4.6 \%)$ \\
\hline Convulsion & $3(3.4 \%)$ \\
\hline Others & $15(17.2 \%)$ \\
\hline
\end{tabular}

\section{Discussion}

Despite recent advances in stroke therapy, the majority of stroke patients do not seek immediate medical attention [4]. Even in developed countries like USA [4, 6], UK [8] and France [9], there is a lack of knowledge amongst people about warning symptoms and risk factors of stroke. In a multi-center survey in USA, over one-half of patients at increased risk for stroke were unaware of their risk factors
[10].

Stroke is one of the major morbidity and mortality factors in poor countries like Bangladesh and there have been no studies regarding the knowledge about warning symptoms and risk factors amongst stroke patients in this country. There is often a delay in transporting and admitting patients with stroke due to various reasons and this is a major contributory factor for increasing the morbidity and mortality of such patients. Translating knowledge of stroke warning signs into appropriate action is critical to decrease this delay [11]. An increase in the speed of hospitalization after the onset of stroke depends primarily on the level of awareness amongst people regarding the importance of golden hour/s as well as many other factors that have been mentioned earlier. Identification of the major risk factors of stroke and its clinical presentation has a direct implication for the prevention and rapid intervention of a stroke patient with the possible therapeutic measures [3].

In our study, the demographic characteristics of the relatives of stroke patients shows that lower qualification and low-income groups comprised almost 3/4th of the affected population. Almost the entire group of relatives preferred hospital care as their first option in case of an acute stroke. Unconventional methods of treatment like witchcraft and herbal interventions as options for treatment are popular in only a small minority (6\%), which is encouraging compared to the overall health facilities. Since half of the population (47.3\%) did not know about any of the preventive measures for stroke, it is imperative that educational campaigns target the entire population for better results.

Improvement of awareness about treatment options is a positive outcome of this study but lot of work needs to be done to make people aware about the need for early transportation and admission to the hospital within the golden hour/s of treatment for better outcome.

In poor countries like Bangladesh, cost of treatment is a major inhibitory factor for seeking medical support as highlighted earlier also by Andaleeb et al [12]. Our study was in agreement with these results as majority of the participants $(45.5 \%)$ pointed out the cost of treatment as the major inhibitory factor for seeking medical support. Difficult transportation (32.7\%) was also an important factor preventing people from seeking any help. Attention towards these factors will need a long term planning, which is indirectly related to overall economic growth of the country and living conditions of the population. More than half of the population (50.9\%) looked to be worried about the expenses needed for treatment of stroke and termed it very expensive for Bangladeshi population in general. This could be a factor responsible for the delay in seeking early treatment of stroke patients by their close relatives.

We found a gap between the lifestyle and knowledge of risk factors. Stressful life is understood to be a major risk factor for stroke in Bangladesh followed by hypertension and diabetes, which is not consistent with studies that highlight high blood pressure and smoking as the most 
commonly identified risk factors in Ohio [13], South Korea [14],Hong Kong [15] and Australia [16]. This may be related to the multiple problems including low income and other economic issues in this population compared to the Western world, where health care is easily available for everyone.

Overall awareness among relatives about warning signs and complications of stroke is seen in majority of the Bangladeshi population, which differs from other developing countries (Uganda) [17]. However awareness about early intervention during the golden hour/s of treatment for stroke was seen in only about one-fourth of the relatives, which is not encouraging considering the advances in treatment that are available for such patients. This may be due to inadequate stroke related awareness about early intervention benefits, lack of proper primary health care system and referral services.

The role of mass media in raising awareness of stroke is of utmost importance [18] and would positively influence emergency department visits by stroke patients [19]. In an efficacy study by Stern et al. [20], it was shown that the information on stroke can be successfully increased by using media including television, newspapers and magazines as well as family and friends followed by health professionals and educational campaigns. This was consistent with our study.

\section{Conclusions}

Knowledge of stroke was significantly associated with level of education but not income, sex or gender. There is lack of primary health care involvement in management of, stroke patients in Bangladesh and providing basic training to health care workers will definitely improve quick referral of these patients to treatment centers. Furthermore, we believe that the use of public media and intervention by the government to organize stroke related health camps across the country could probably change the level of the population's knowledge of and attitude towards stroke.

\section{Acknowledgements}

We thank our supervisor Prof. Ridwanur Rahman, Head of Medicine, Sh. SMCH for guiding us through this study and his continued support. We would also like to thank Prof. Musarrat Haque, Head of Community Medicine, Sh. SMCH for lending her help and support at all times. We are extremely grateful to all the Medicine units in Sh. SMCH and Dr. Mohammad Abdullah Yusuf, Assistant Professor, NINS, Dhaka for their support. Our sincere thanks and gratitude to Dr. Bashir Bhat, Senior Consultant, Muscat Private Hospital in Oman and Prof. Mushtaq Lone of Government Medical College, Srinagar, for their valuable inputs and guidance.

\section{REFERENCES}

[1] Islam $\mathrm{MN}$, Moniruzzaman $\mathrm{M}$, et al. Burden of stroke in Bangladesh. Int J Stroke. 2013 April; 8(3): 211-213.

[2] Sacco RL, Kasner SE, et al. AHA/ASA Expert Consensus an Updated Definition of Stroke for the $21^{\text {st }}$ Century. Stroke. 2013; 44: 2064-2089.

[3] Borhani HA, Karimi AA, Amiri A, et al. Knowledge and attitude towards stroke risk factors, warning symptoms and treatment in an Iranian population. Med Princ Pract. 2010; 19(6): 468-472.

[4] Williams LS, Bruno A, Rouch D, Marriott DJ. Stroke patient's knowledge of stroke: Influence on time of presentation. Stroke 1997; 28: 912-5.

[5] Paresh P, Sheetal S, Sagal H. Stroke: classification and diagnosis. Clinical Pharmacist. 2011 Jan; 3: 200.

[6] Kothari R, Sauerbeck L, Jauch E, Broderick J, Brott T, Khoury J, et al. Patient's awareness of stroke signs, symptoms and risk factors. Stroke 1997; 28: 1871-5.

[7] Weltermann BM, Homann J, et al. Stroke Knowledge among Stroke Support Group Members. Stroke. 2000; 31: 12301233.

[8] Carroll C, Hobart J, Fox C, Teare L, Gibson J. Stroke in Devon: Knowledge was good, but action was poor. J Neurol Neursurg Psychiatr 2004; 75: 567-71.

[9] Derex L, Adeleine P, Nighoghossian N, Honnorat J, Trouillas P. Knowledge of strokes in patients admitted to a French Stroke Unit. Rev Neurol 2004; 160: 331-7.

[10] Samsa GP, Cohen SJ, Goldstein LB, Bonito AJ, Duncan PW, Enarson C, et al. Knowledge of risk among patients at increased risk for stroke. Stroke 1997; 28: 916-21.

[11] Fussman C, Rafferty AP, et al. Lack of Association between Stroke Symptom Knowledge and Intent to Call 911. Stroke. 2010; 41: 1501-1507.

[12] Andaleeb SS, Siddiqui N, Khandakar S. Patient satisfaction with health services in Bangladesh. Health Policy and Planning 2007; 22: 263-273.

[13] Pancioli AM, Broderick J, Kothari R, et al. Public perception of stroke warning signs and knowledge of potential risk factors. JAMA 1998; 279: 1288-1292.

[14] Kim JS, Yoon SS: Perspectives of stroke in persons living in Seoul, South Korea: a survey of 1,000 subjects. Stroke 1997; 28: $1165-1169$.

[15] Cheung RTF, Li LSW, Mak W, et al. Knowledge of stroke in Hong Kong Chinese. Cerebrovasc Dis 1999; 9: 119-123.

[16] Commonwealth of Australia: The National Tobacco Campaign. www.quitnow.info.com (accessed December 16, 1999).

[17] Nakibuuka J, Sajatovic M, Katabira E, et al. Knowledge and Perception of Stroke: A Population-Based Survey in Uganda. ISRN Stroke, vol. 2014, Article ID 309106, 7 pages, 2014. 
doi:10.1155/2014/309106.

[18] Davis SM, Community stroke education using mass media: past results and future implications. Stroke. 2007; 38: 20342035.

[19] Hodgson C, Lindsay P, Rubini F. Can mass media influence emergency department visits for stroke? Stroke 2007; 38: 2115-2122.

[20] Stern EB, Berman M, Thomas JJ, Klassen AC: Community education for stroke awareness: an efficacy study. Stroke 1999; 30: 720-723. 